\title{
Correspondence
}

\section{Is Hepatorenal Syndrome a Diagnosis for the Emergency Physician?}

Acute kidney injury (AKI) in the patient with decompensated liver disease is common and signifies a poor prognosis.' Hepatorenal syndrome (HRS) is a potential cause of AKI in patients with acute or chronic liver disease. In the International Journal of Medical Students, Tan et al reported a case of HRS diagnosed in the emergency department in a patient who presented with fluid overload and AKI on a background of cryptogenic liver cirrhosis. ${ }^{2}$ The accompanying review on the topic was an excellent aspect of the article.

The diagnostic possibilities in a cirrhotic patient are broad and several are deserving of prompt treatment, including hypovolemia (such as from gastrointestinal bleeding), sepsis, and nephrotoxic drugs. A prognostic study of 562 patients with AKI and cirrhosis incriminated HRS in only $13 \%$, while infection was responsible for $46 \%{ }^{3}$ Indeed, it has been suggested that the diagnosis of HRS is one of exclusion. The initial management requires adequate intravascular volume expansion with albumin infusion for 2 days. ${ }^{4}$ HRS is then suspected when there is no response, and treatment for such should be considered then. This consists of the administration of vasoconstrictors, such as terlipressin (a vasopressin analogue) or alpha-adrenergic agents (e.g. noradrenaline and midodrine), combined with albumin. ${ }^{4}$ Ischemia may result from the use of vasoconstrictors and thus caution must be exercised, especially in patients with or at risk for coronary artery disease, peripheral vascular disease or cerebrovascular disease. ${ }^{5}$ In addition, the use of vasoconstrictors in acute tubular necrosis, pre-renal azotemia or obstructive AKI could further aggravate renal function in this group of patients. In this regard, the role of the emergency physician (EP) in diagnosing and managing HRS is traditionally limited.

A survey of bibliography databases including Pubmed with MeSH terms "Hepatorenal syndrome" and "Emergency Medicine" yielded few studies supporting the diagnosis of HRS in the emergency department. However, this may change in the future as novel biomarkers such as neutrophil gelatinase-associated lipocalin (NGAL) allow early differentiation of different causes of AKI in the cirrhosis patient. ${ }^{6}$

The authors should be commended on providing an interesting perspective. The EP must have a working knowledge of HRS and its prognostic significance given the appropriate clinical context, but in most systems of care would not have sufficient clinical information to establish a diagnostic certainty beyond the treatment threshold. We put forth the idea that EPs have a more important role in such cases to exclude or treat precipitating or co-existing emergencies including gastrointestinal bleeding and spontaneous bacterial peritonitis, and to initiate intravascular volume expansion.

Andrew F. W. Ho, ${ }^{1}$ Pin P. Pek, ${ }^{2}$ Tiing L. Ang. ${ }^{3}$

'Emergency Medicine Residency Program, SingHealth Services, Singapore. 2Emergency Medicine, Singapore General Hospital, Singapore.

${ }^{3}$ Gastroenterology, Changi General Hospital, Singapore.

andrew.ho@mohh.com.sg
References

1. Moreau R, Lebrec D. Acute renal failure in patients with cirrhosis: perspectives in the age of MELD. Hepatology. 2003 Feb;37(2):233-43.

2. Tan W], Tiruchittampalam M, Loo Y. Hepatorenal syndrome in the emergency department: a case report. Int J Med Students. 2014 Nov-2015 Mar;3(1):51-4. 3. Martín-Llahí M, Guevara M, Torre A, Fagundes C, Restuccia T, Gilabert R, et al. Prognostic importance of the cause of renal failure in patients with cirrhosis. Gastroenterology. 2011 Feb;140(2):488-96.

4. Angeli P, Gines P, Wong F, Bernardi M, Boyer TD, Gerbes A, et al. Diagnosis and management of acute kidney injury in patients with cirrhosis: revised consensus recommendations of the International Club of Ascites. Gut. 2015 Apr;64(4):531-7.

5. Ginès P, Schrier RW. Renal failure in cirrhosis. N Engl J Med, 2009 Sep 24;361(13):1279-90.

6. Fagundes C, Pépin MN, Guevara M, Barreto R, Casals C, Solà E, et al. Urinary neutrophil gelatinase-associated lipocalin as biomarker in the differential diagnosis of impairment of kidney function in cirrhosis. J Hepatol. 2012 Aug;57(2):267-73.

\section{Acknowledgments: None.}

Conflict of Interest Statement at Funding: The Author has no funding, financial relationships or conflicts of interest to disclose.

Author Contributions: Conception and design the work/idea: AFWH, Write the manuscript, Critical revision of the manuscript, Approval of the final version: AFWH, PPP, TLA.

Cite as: Ho AFW, Pek PP, Ang TL. Is Hepatorenal Syndrome a Diagnosis for the Emergency Physician?. Int J Med Students. 2015 Apr-Aug;3(2):120.
Submission: Apr 8, 2015 Acceptance: Jul 3, 2015 Publication: Jul 14, 2015 